\title{
ANALYSIS OF THE EFFECT OF CYCLIC LOADING ON COTTON-SPANDEX KNITTED FABRIC
}

\author{
[Prof. Dr. Magdi El Messiry, Dr. Abeer Mohamed]
}

\begin{abstract}
-knitted fabrics find numerous applications in sportswear fabric industry, during their use it can be subjected to loading-unloading due to the body movements which can be indirectly affected by the dynamic elastic recovery value of the fabrics. The cyclic loads lead to the redistribution of fibers in the yarn structure, because they tend to get the minimum level of energy. Dimensional properties of knitted fabric are widely affected by the externally applied forces that could involve permanent deformation. Cotton/Spandex knitted fabrics are widely used for several applications. In this work, an attempt was done to analyze the effect of cyclic loading on cotton/spandex knitted fabric subjected to the different levels of cyclic loading under different values of initial extensions. Knitted fabric mechanical properties with different percentages of spandex were tested. The fabric properties and the number of cycles indicate the change of the residual extension and the drop in the fabric strength and stiffness.
\end{abstract}

Keywords - spandex knitted fabric, cyclic loading, elastic recovery, and sportswear fabrics

\section{Introduction}

Knitted fabrics are very popular in clothing industry. The loss of elasticity during use is one of the most important problems that could influence the long-term reliability of knitted garments. In sportswear fabrics, a part of the socalled wear and loss of shape undoubtedly arises from repeated excessive loading in localized areas. To improve the recovery performance of knit fabrics, it is now common practice to co-knit a small amount of spandex fiber or yarn with companion cotton yarn. The structural parameters and condition of cyclic loading play a basic role in the fatigue behavior of textile materials. At fatigue loading, dimensional properties of this category of knitted fabric are widely affected by the externally applied forces that could involve permanent deformation [1-2]. Fatigue is the failure or decay of the mechanical properties of a material after the application of repeated stress or strain. The structural parameters and condition of cyclic loading play a basic role in the fatigue behavior of textile materials. The effects of loading parameters and structural specifications on the fatigue properties of textile fabrics have been investigated by several researchers[3-7], as there are some general features of all fatigue processes: a) The greater the applied stress, the shorter the fatigue life. b) Damage is cumulative. Materials do not fully recover when rested. c) High cycle fatigue strength can be described by stress-based parameters.

prof.dr. Magdy El Messiry

Engineering / Alexandria University

Egypt

Dr. Abeer Mohamed

Engineering / Alexandria University

Egypt d) Low cycle fatigue is associated with widespread plasticity, thus a strain-based parameter should be used. Main factors affecting fatigue life are:1) material type, 2) quality of the surface, 3) material internal structure, 4) strain rate, 5) environmental conditions and exposure time can cause degradation, softening, or hardening, 6) the operating temperature over which the textile material is exposed affects the mechanical properties and fatigue as well. Elmessiry etal[8] Stuied the effect of the cyclic loading on the knitted fabric bagging. The objectives of this study are to analyse the effect of applying a tension-tension cyclic loading on the behavior/ of knitted fabric with different spandex percentage.

\section{Experimental}

\section{A. Materials}

TABLE I. PHYSICAL PROPERTIES OF KNITTED FABRICS

\begin{tabular}{|c|c|c|c|c|c|c|}
\hline $\begin{array}{l}\text { Fabric } \\
\text { code }\end{array}$ & $\begin{array}{l}\text { Fabric } \\
\text { design }\end{array}$ & $\begin{array}{l}\text { Yarn } \\
\text { count } \\
\text { (tex) }\end{array}$ & $\begin{array}{l}\text { Lycra } \\
\text { count(tex) }\end{array}$ & $\begin{array}{l}\text { Lycra } \\
\%\end{array}$ & $\begin{array}{l}\text { Weight } \\
\left(\mathrm{gm} / \mathbf{m t}^{2}\right)\end{array}$ & $\begin{array}{l}\text { Thickness } \\
(\mathbf{m m})\end{array}$ \\
\hline $\begin{array}{l}\text { DJ } \\
2 \%\end{array}$ & $\begin{array}{l}\text { double } \\
\text { jersey }\end{array}$ & $\begin{array}{l}\text { combed } \\
\text { cotton } \\
\text { yarn } \\
8.9\end{array}$ & 4.9 & 2 & 128 & 0.56 \\
\hline $\begin{array}{l}\text { DJ } \\
10 \%\end{array}$ & $\begin{array}{l}\text { double } \\
\text { jersey }\end{array}$ & $\begin{array}{l}\text { combed } \\
\text { cotton } \\
\text { yarn } \\
16.3\end{array}$ & 2.62 & 10 & 264 & 0.99 \\
\hline $\begin{array}{l}\text { DJ } \\
2.5 \%\end{array}$ & $\begin{array}{l}\text { double } \\
\text { jersey }\end{array}$ & $\begin{array}{l}\text { combed } \\
\text { cotton } \\
\text { yarn } \\
19.6\end{array}$ & 4.9 & 2.5 & 187 & 0.66 \\
\hline SJ 5\% & $\begin{array}{l}\text { single } \\
\text { jersey }\end{array}$ & $\begin{array}{l}\text { combed } \\
\text { cotton } \\
\text { yarn } \\
14.75\end{array}$ & 2.4 & 5 & 208 & 0.71 \\
\hline $\begin{array}{l}\text { DJ } \\
\text { 0\% }\end{array}$ & $\begin{array}{l}\text { double } \\
\text { jersey }\end{array}$ & $\begin{array}{l}\text { combed } \\
\text { cotton } \\
\text { yarn } \\
15.4\end{array}$ & 0 & 0 & 260 & 0.7 \\
\hline
\end{tabular}

\section{B. $\quad$ Tensile testing}

The tensile testing was performed to investigate the fundamental mechanical characterizations by Instron-4411 tester at $20^{\circ} \mathrm{Croom}$ temperature and $65 \%$ relative humidity. 
Proc. of The Fifth Intl. Conf. On Advances in Mechanical, Aeronautical and Production Techniques - MAPT 2016 Copyright (C) Institute of Research Engineers and Doctors, USA .All rights reserved.

ISBN: 978-1-63248-090-3 doi: 10.15224/ 978-1-63248-090-3-41

\section{c. Cyclic load application}

In order to apply a cyclic load on the samples, the experiments were carried out according to ASTM D6588 on fatigue testing machine which gives 1350 cycle per min as shown in "fig 1 ".

The tester consists of two clamps, the upper clamp moves upward manually by using an arm to give the fabric a certain extension. The lower clamp moves automatically upwards and downwards, respectively, using a motor to apply a certain number of cycles on the fabric causing fatigue stresses to the fabric.

At the start of the test, the lower jaw will be pushed to the upper position of the cycle to create a certain force $\mathrm{p}_{\mathrm{m}}$. The reciprocation of the lower jaw will change the value of $p_{m}$ as shown in "fig 2".

The value of the number of cycles is varied with values of: $10000,20000,50000$ cycles, in each case the initial extension is varied as $20 \%, 30 \%, 40 \%$, and $50 \%$ of its initial length. The set-up gives the possibility to change the values of $\mathrm{p}_{\min }$ and the value of the number of cycles/min. In all cases the value of $p_{\min }$ is changed by extending the sample with a certain percentage of the initial length.
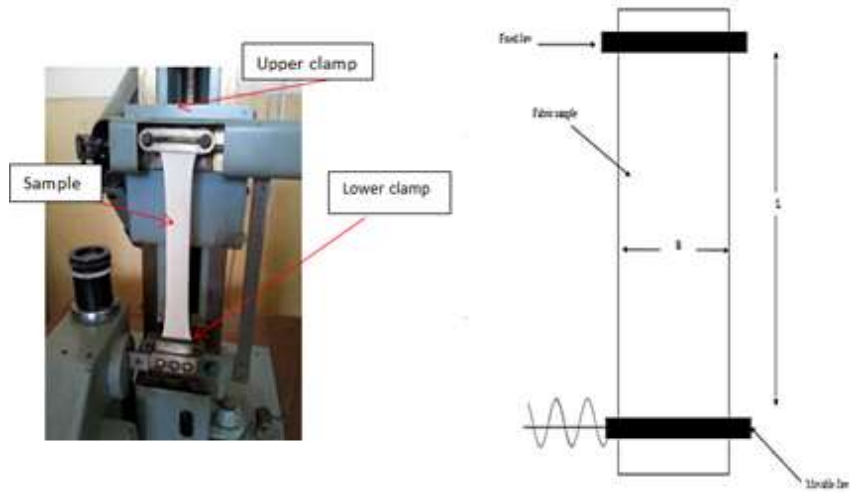

Figure 1. Dynamic uni-axial loading tester

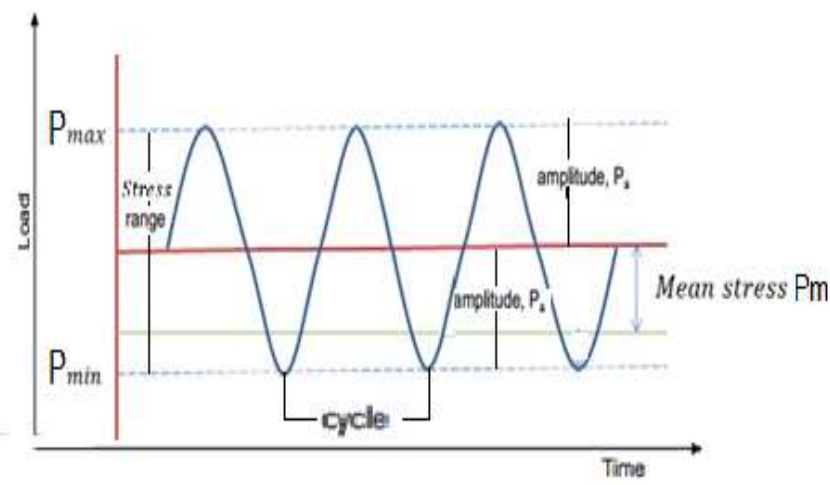

Figure 2. Schematic diagram of the device to apply

TABLE II. THE MECHANICAL PROPERTIES OF THE SAMPLES

\begin{tabular}{|l|l|l|l|}
\hline $\begin{array}{l}\text { Fabric } \\
\text { code }\end{array}$ & $\begin{array}{l}\text { Work of } \\
\text { rupture (N.m) }\end{array}$ & $\begin{array}{l}\text { strength } \\
(\mathbf{N})\end{array}$ & $\begin{array}{l}\text { Breaking } \\
\text { extension \% }\end{array}$ \\
\hline DJ 2\% & 0.831 & 88.11 & 55.035 \\
\hline DJ 10\% & 2.219 & 151.630 & 70.347 \\
\hline DJ 2.5\% & 1.447 & 113.89 & 51.535 \\
\hline SJ 5\% & 1.388 & 75.34 & 105.048 \\
\hline DJ 0\% & 1.6 & 90.8 & 81.8 \\
\hline
\end{tabular}

\section{A. Knitted fabric behavior under cyclic loading}

The application of uni-axial load on the knitted fabric causes an extension of the loop in the direction of the load, as shown in "fig 3"; on Wales-wise direction, at first, the loops will be deformed in both directions $\mathrm{x}$ and $\mathrm{y}$ as the yarns move towards the knitting loop axis.

The increasing of load leads to the increase in the compression of the knitting loop in the width direction " $x$ " and decreasing in knitting loop angle, a matter that cause yarns at loop leg to be jammed to each other. By continues increasing the load, the knitting loop angle continues to decrease until the yarns become tightly packed and the structure is jammed such that no further movement of yarns can take place. The increase of the loop length is due to the straightened of the loop and the contraction in the fabric width. The yarns are affected by the load after fabric reaches jamming point. From the mechanical point of view, the fabric behaves like a structure rather than a continuous material. If loading continues increasing, after "jamming state" the yarn strain will define mainly the fabric strain. The yarn loop legs angle reduces under further loading of the fabric, as illustrated in "fig 4".
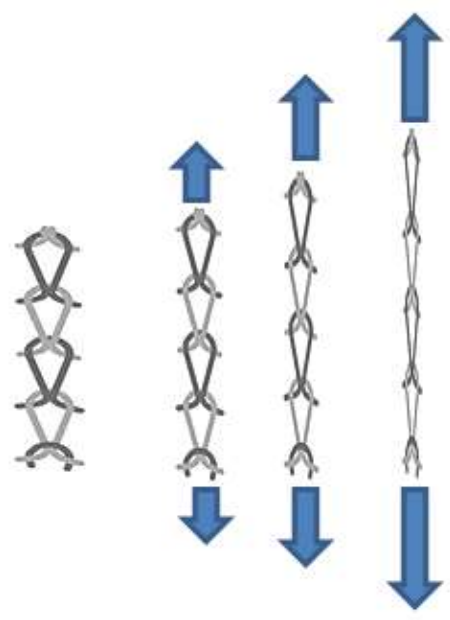

Figure 3. Loop shape under uni-axial force

\section{Results and discussion}

Five knitted fabrics are used with mechanical properties as given in table 2 . 
Proc. of The Fifth Intl. Conf. On Advances in Mechanical, Aeronautical and Production Techniques - MAPT 2016 Copyright (C) Institute of Research Engineers and Doctors, USA .All rights reserved.

ISBN: 978-1-63248-090-3 doi: 10.15224/ 978-1-63248-090-3-41

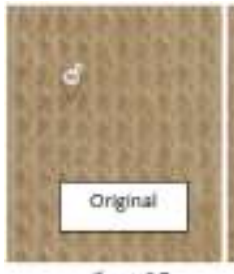

$\emptyset=60$

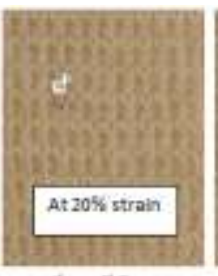

$\emptyset=50$

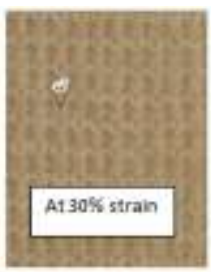

$\emptyset \sim 45$

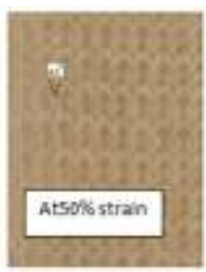

$\emptyset-43$

Figure 4. Change of loop angle under fabric strain

Consequently, the jamming condition of the fabric will differ if the applied load is in the Wales-wise or Course-wise direction. This is clear from the load elongation curve illustrated in "fig 5".

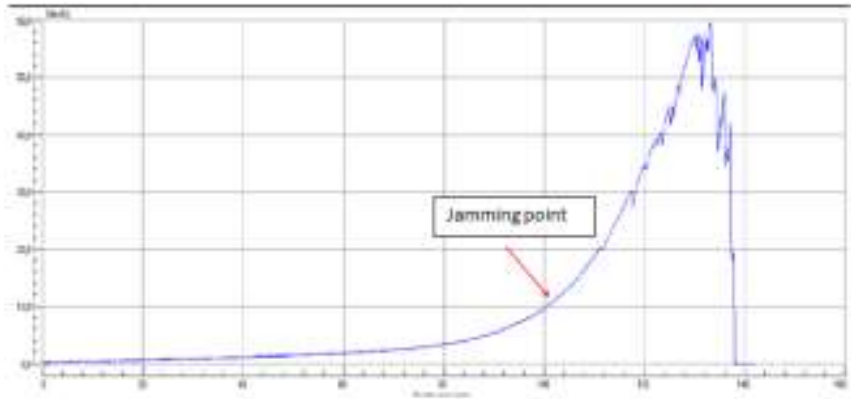

Courses-wise $133.18 \%$

Fabric DJ $2 \%$

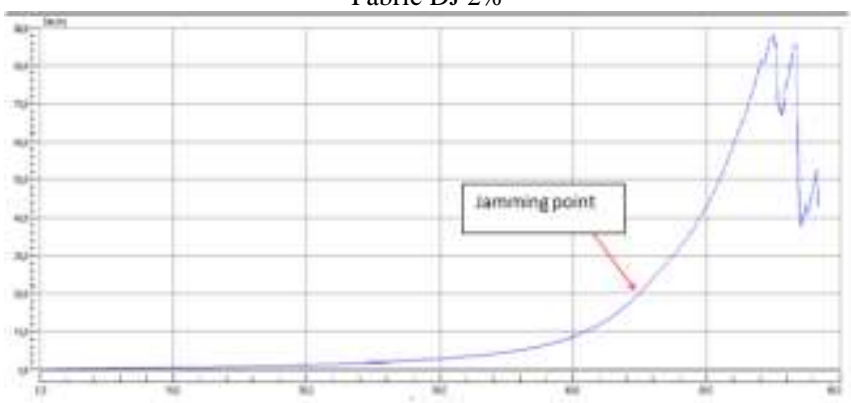

Wales-wise $55.035 \%$

Fabric DJ 2\%

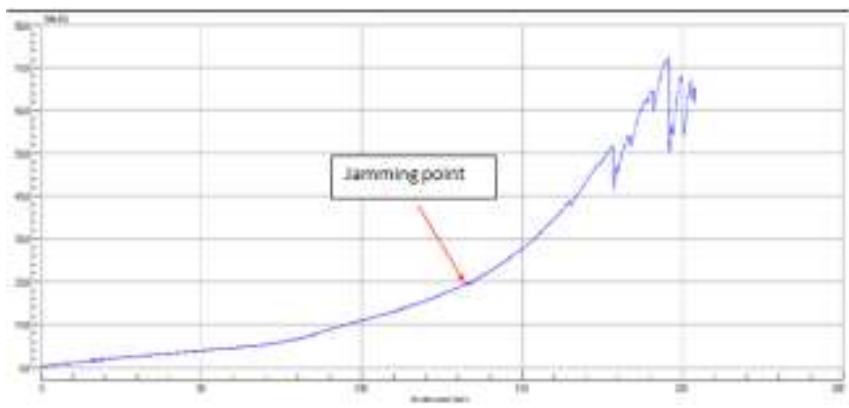

Course-wise 195.599\%

Fabric DJ $10 \%$

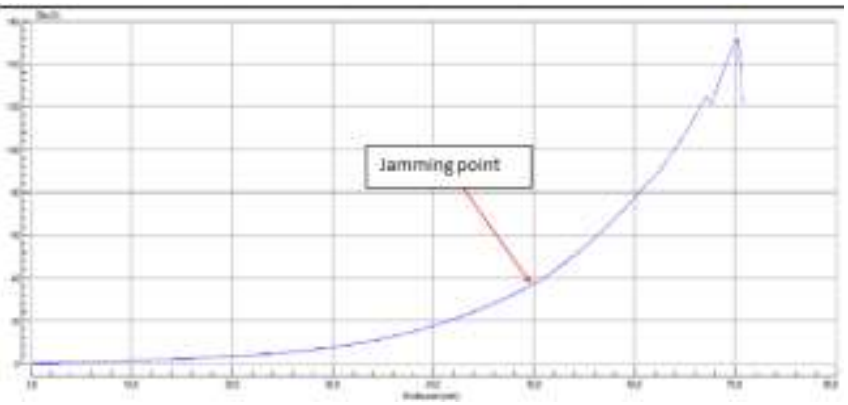

Wales-wise $70.347 \%$

Fabric DJ 10\%

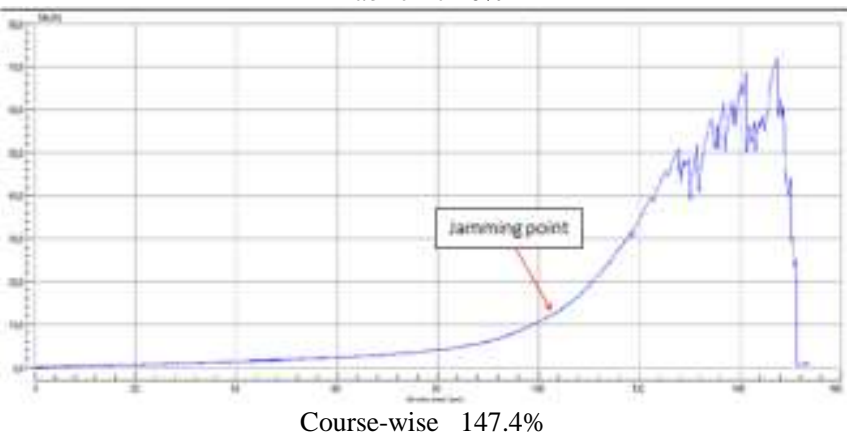

Fabric SJ 5\%

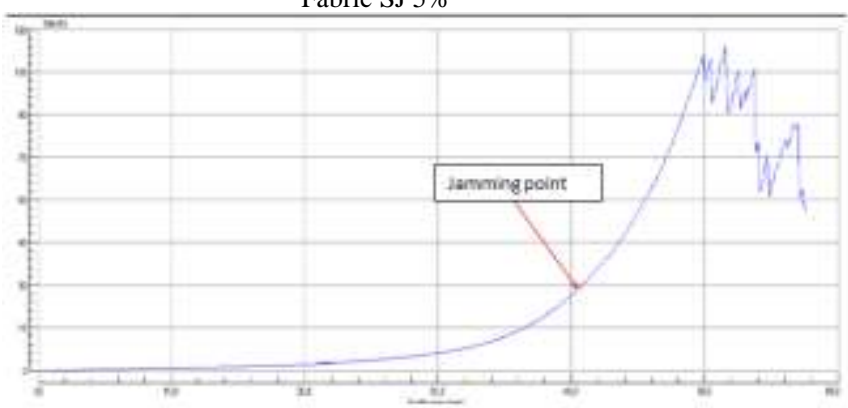

Wales-wise $51.53 \%$

Fabric SJ 5\%

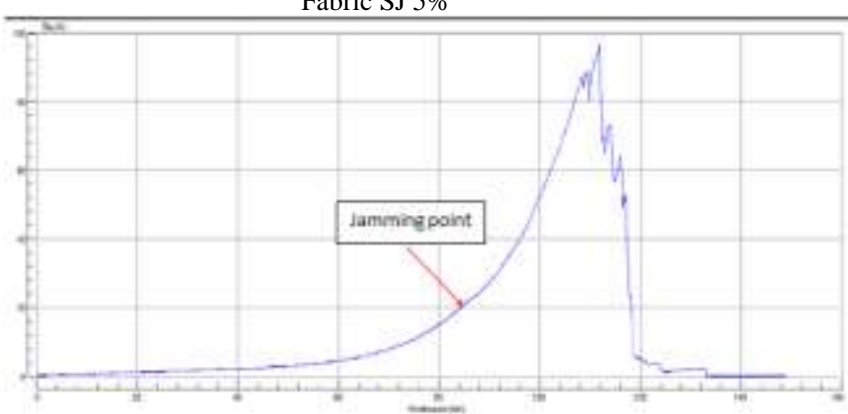

Course-wise $111,865 \%$

Fabric DJ 2.5\%

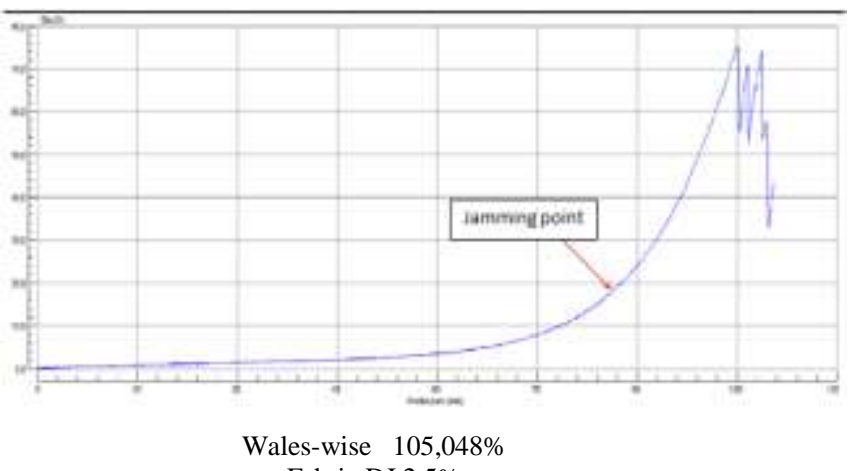

Fabric DJ 2.5\%

Figure 5. the jamming conditions of different fabrics in Wales and Course directions 
Proc. of The Fifth Intl. Conf. On Advances in Mechanical, Aeronautical and Production Techniques - MAPT 2016 Copyright (C) Institute of Research Engineers and Doctors, USA .All rights reserved.

ISBN: 978-1-63248-090-3 doi: 10.15224/ 978-1-63248-090-3-41

"Fig 5" illustrates the load elongation curve in the Wales direction and Course direction for different fabrics. In case of loading in Wales direction, the jamming point of the loop will reach at lower elongation of the fabric than in the case of applying load in the Course direction, due to the fact that the fabric elongation in Wales direction is usually less.

The value of the jamming force will depend on the specifications of the fabric and the percentage of the Lycra used as well as the area of the fabric under loading, as illustrated in figures $(6, a, b, c)$.

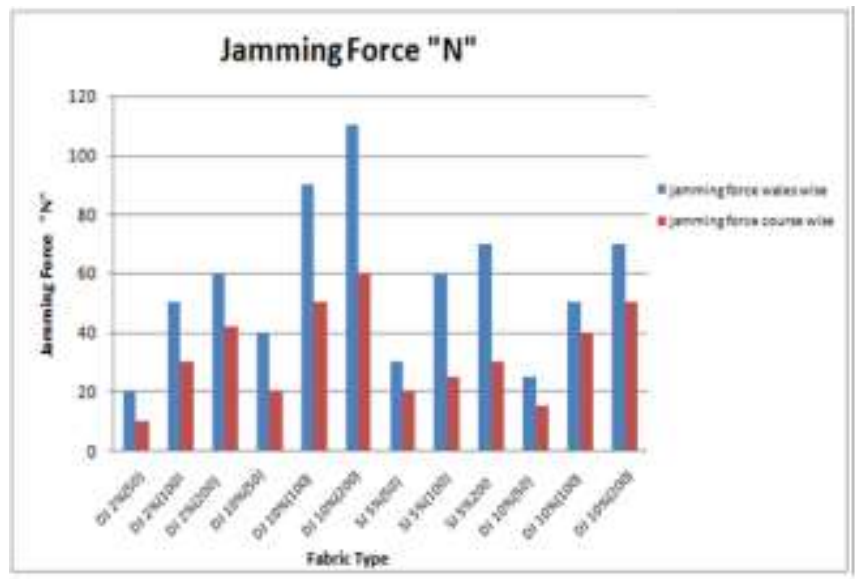

(a)

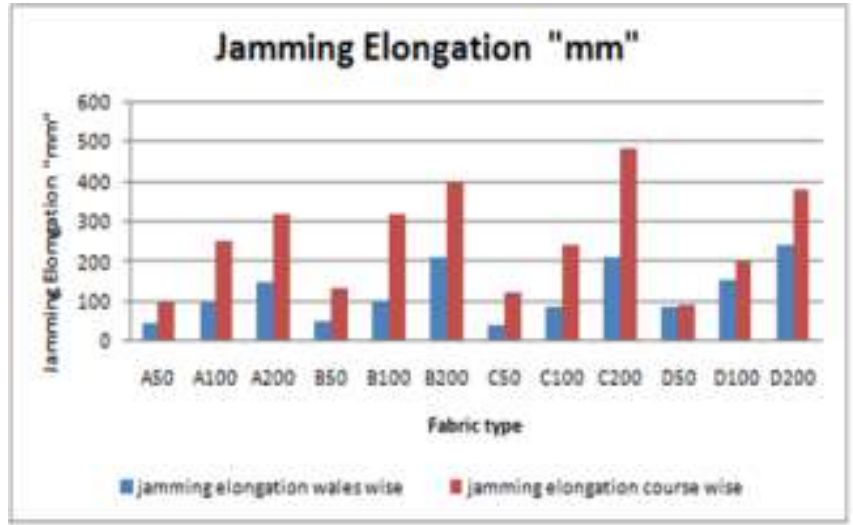

(b)

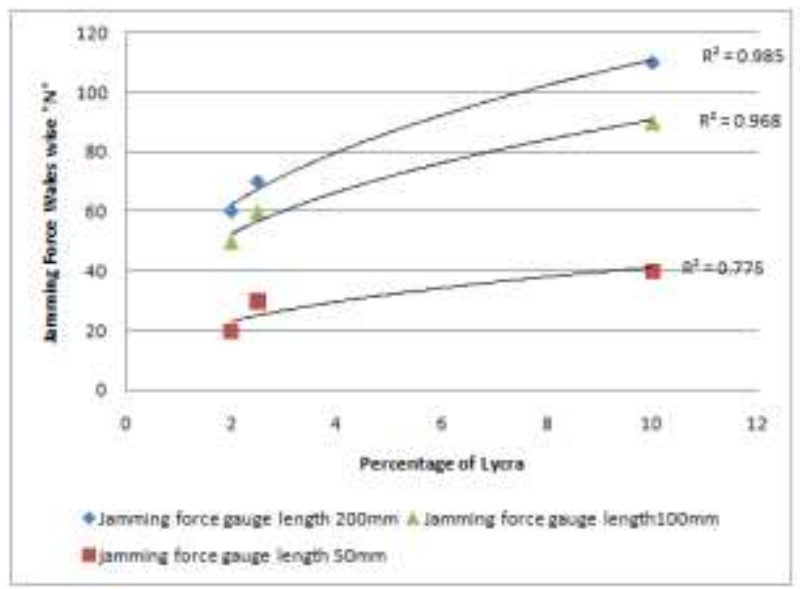

(c)

Figure 6(a,b,c). Jamming force, jamming extension, and percent of Lycra at jamming conditions
The increase of the fabric area under the applied force increases the jamming force and jamming elongation of the fabric since more structure will contribute in defining the jamming conditions.

\section{B. Effect of cyclic loading on tensile properties of fabrics}

When the initial extension applied on the sample, the maximum load $\mathrm{P}_{\max }$ in the case of fabric deform is less than that of jamming conditions. The effect of the cyclic loading will lead to the movement of the yarn under low strain, therefore may achieve reorientation of the fibers in the yarn and increase the stiffness of the yarns. It will result in stiffer fabric. The Young's modulus seems to be higher depending on the number of cycles and the value of $\mathrm{P}_{\max }$ as well as the percentage of Lycra. The increase of the Lycra percentage reduces the effect of the cyclic loading and the breaking load will have minor changes. Figure (7-a,b,c,d,e) illustrate the effect of the load extension curve for different fabrics under the change of initial extension of the applied cyclic load.

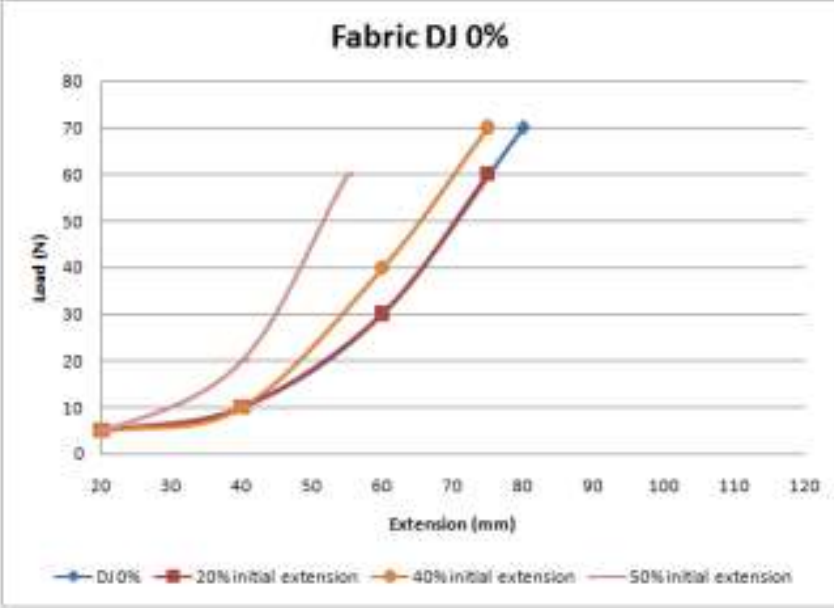

Figure 7a. Load-extension curves for cotton knitted fabric DJ $0 \%$ before fatigue (original) and after fatigue at 50000 cycles

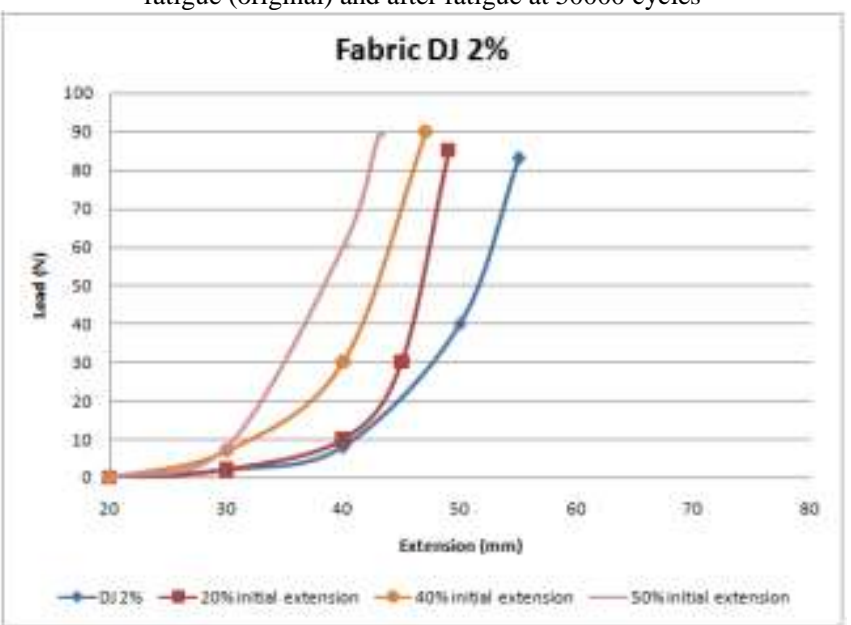

Figure 7b. Load-extension curves for cotton -Lycra knitted fabric DJ 2\% before fatigue (original) and after fatigue at 50000 cycles 
Proc. of The Fifth Intl. Conf. On Advances in Mechanical, Aeronautical and Production Techniques - MAPT 2016 Copyright (C) Institute of Research Engineers and Doctors, USA .All rights reserved.

ISBN: 978-1-63248-090-3 doi: 10.15224/ 978-1-63248-090-3-41

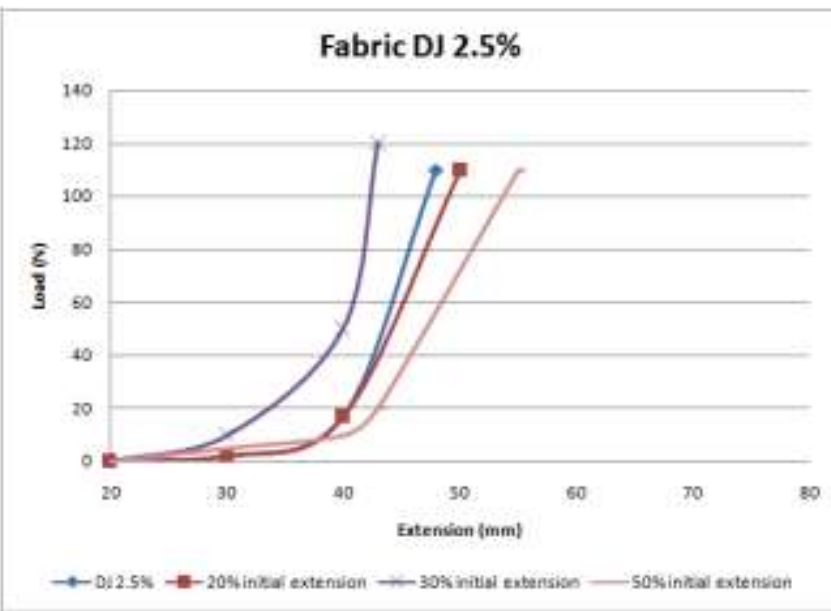

Figure 7c. Load-extension curves for cotton -Lycra knitted fabric DJ 2.5\% before fatigue (original) and after fatigue at 50000 cycles

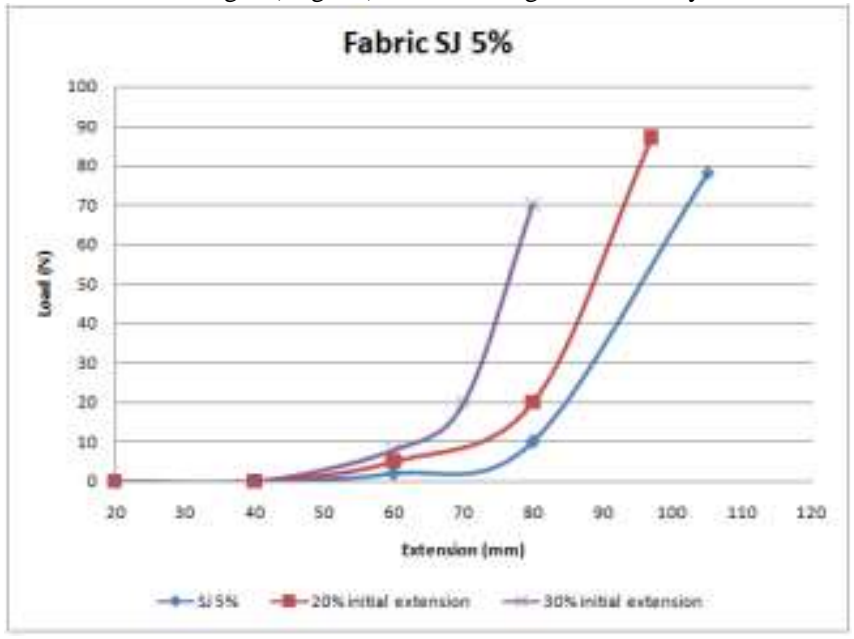

Figure 7d. Load-extension curves for cotton -Lycra knitted fabric SJ 5\% before fatigue (original) and after fatigue at 50000 cycles

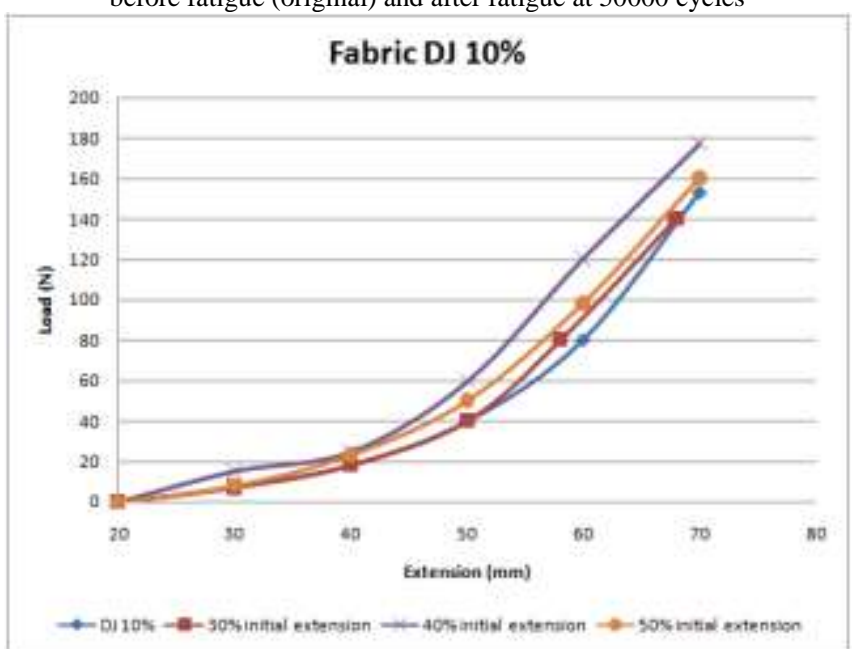

Figure 7e. Load-extension curves for cotton -Lycra knitted fabric DJ 10\% before fatigue (original) and after fatigue at 50000 cycles

These curves prove the above analysis. The application of the cyclic load on the fabric while it is in the jamming condition, i.e. the looped yarn is strained, will cause a real strain in the yarn leading to the change in the yarn structure. Figure (8- a, b, c, d) illustrates the effect of the cyclic loading on different jammed fabrics.

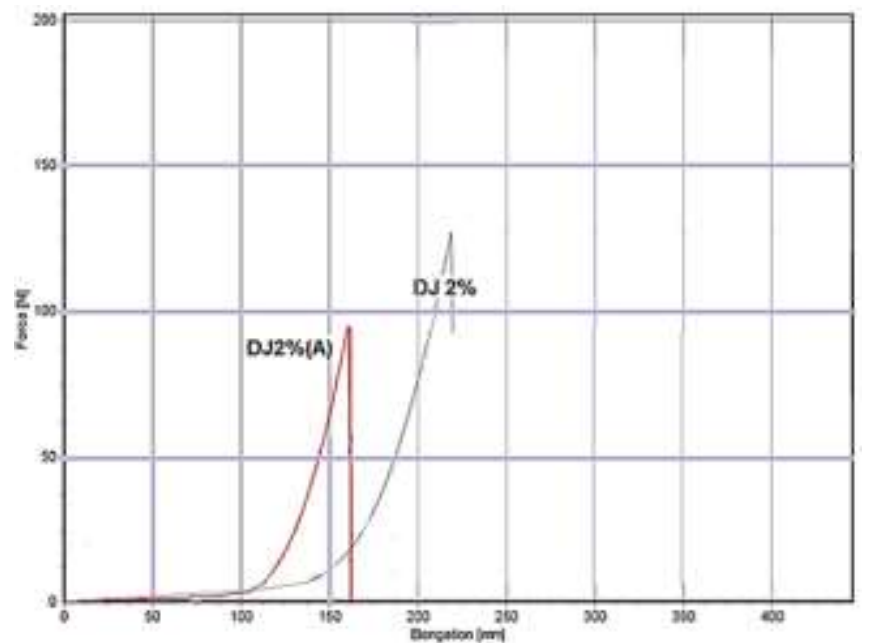

(a)

Figure 8a. Load-extension curves for cotton-Lycra knitted fabric DJ 2\% before cyclic loading (original) and jammed knitted fabric DJ 2\%(A) after applying cyclic loading of 50000 cycles

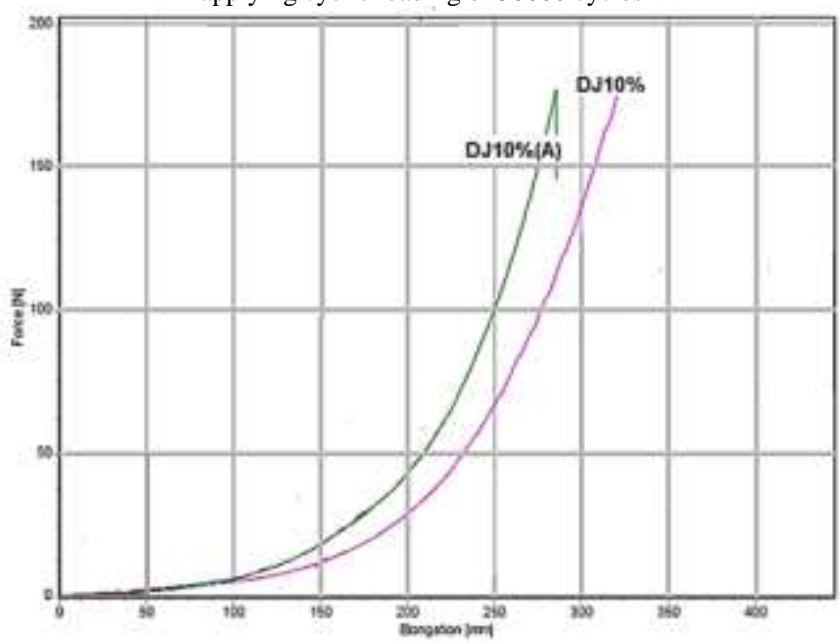

(b)

Figure 8b. Load-extension curves for cotton-Lycra knitted fabric DJ $10 \%$ before cyclic loading (original) and jammed knitted fabric DJ 10\%(A) after applying cyclic loading of 50000 cycles

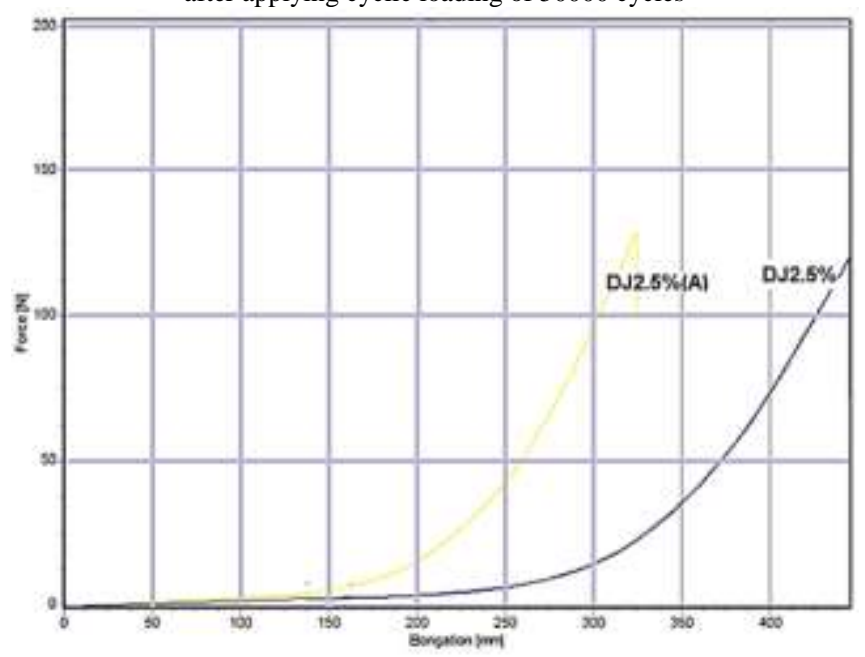

(c)

Figure 8c. Load-extension curves for cotton-Lycra knitted fabric DJ $2.5 \%$ before cyclic loading (original) andjammed knitted fabric DJ $2.5 \%$ (A) after applying cyclic loading of 50000 cycles 


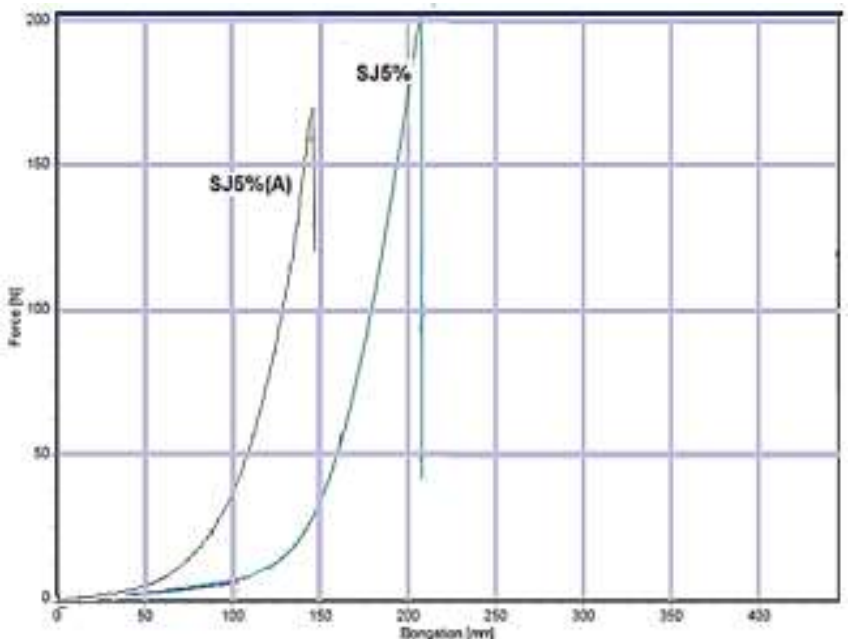

(d)

Figure 8d. Load-extension curves for cotton-Lycra knitted fabric SJ 5\%before cyclic loading (original) and jammed knitted fabric SJ 5\%(A) after applying cyclic loading of 50000 cycles

Figure (8- a,b,c, d) illustrates the effect of applying cyclic loads after tensioning the fabrics to reach the jamming conditions. From figure (8) it can be concluded that the cyclic loading have a very destructive effect on the fabric load extension curve, considerably reducing the breaking load due to the change of the structure of the yarns under the cyclic loading. The fabric Young's Modulus increase depends on the percentage of the Lycra. The higher percentage of Lycra, the damage of the fabric is less. In order to prove that, a single cotton yarn was subjected to 50000 cycles at the same percentage of extension as applied on jammed knitted fabric and the load extension curve is given in figure (9), which indicates the reduction of the breaking load.

About Author (s):

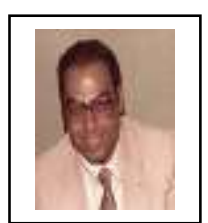

[Dr. Magdi received his bachelor's degree in textiles from Faculty of Engineering, Alexandria University, MSc in Fiber Science and Technology Faculty of Engineering, Alexandria University, and his $\mathrm{PhD}$ in Textile machine design from Moscow Textile University 1971. His dissertation research was to understand the dynamics of the drafting system on spinning machinery. After that he joined Textile Engineering Department, Faculty of Engineering, Alexandria University as faculty member. His research covers: (i) Spinning Tech. (ii) Natural fiber composites (iii) Nanofibers and nanocomposites. He has published more than 140 original research papers, and has leading and participating several projects either National or International universities.

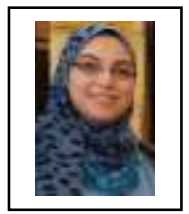

Dr. Abeer Metwally Lecturer at Textile Engineering Department, Faculty of Engineering, Alexandria university, nationality :Egyptian, date of birth 1984 and marital status : married. Graduated 2007 from faculty of Engineering,

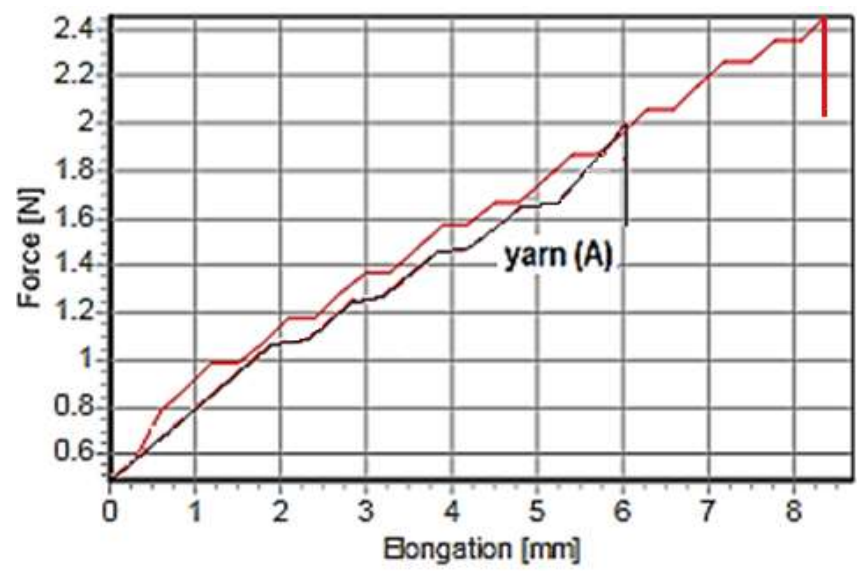

Figure 9. Load-extension curves for cotton yarn before cyclic loading (original) and yarn (A) after applying cyclic loading of 50000 cycles

\section{Conclusion}

The cyclic loading affects the tensile properties of the fabric. To minimize the effect of the dynamic loading on the fabric, it is advisable to use the Lycra yarn. The fabric should not be loaded in the jamming condition to prevent the damage of the yarns due to cyclic loading. Even under low values of cyclic loading, strength, Young's Modulus, and breaking extension will be altered. It is recommended to keep the values of $\mathrm{P}_{\max }$ less than the jamming force of the fabric.

\section{References}

[1] WL Wu, KotakiM, Fujita A, HamadaH, Mechanical Properties of Warp-Knitted, Fabric-Reinforced Composites", Journal of Reinforced Plastics and Composites :Journal of Reinforced Plastics and Composites: October 1993 vol. 12 No. 10:p. 1096-1110.

[2] Sayesh A, JeddiA Tensile Fatigue Behavior of Plain Woven Fabrics Constructed from Textured Polyester Yarn,Iran, Iranian Polymer Journal:, 30 June 2007: 16(6):p. 409-416

[3] Otaghsara M. R. T., Jeddi A. A.A., Mohandesi J. A.; Tensile Property and Fatigue Behaviour of Warp Knitted Fabrics.FIBRES \& TEXTILES in Eastern Europe 2009, Vol. 17, No. 3 (74) pp. 70-75.

[4] Miraftab M, Fatigue Failure of Textile Fibers, the textile institute, wood head publishing in textile: number 86, 2009.

[5] RitchieO,Mechanisms of Fatigue-Crack Propagation in Ductile and Brittle Solids, International Journal of Fracture: 1999:100:p.55-83.

[6] Wthorne A. Subhash K. Batra, Hawthorne A. Davis(NC State); Michael S. Ellison, "Microstructure and Fatigue of Textile and Industrial Fibers", National Textile Center Research Brief: May 1995.

[7] Rajesh D. Anandjiwala, Mike Carmical, and Bhuvenesh C. Goswami. Textile Properties and Static Fatigue Behavior of Cotton Warp Yarns, Textile research Journal:1995:65(3):p.131-149.

[8] El Messiry M, Mohamed A, Investigation of Knitted Fabric Dynamic Bagging for Textile Composite, Textile institute journal: (2015) 